\title{
Author Correction: Deciphering Electron-Shuttling Characteristics of Neurotransmitters to Stimulate Bioelectricity-Generating Capabilities in Microbial Fuel Cells
}

\author{
Bor-Yann Chen ${ }^{1} \cdot$ Yu-Hsiu Lin ${ }^{1} \cdot$ Yun-Chen $\mathrm{Wu}^{1} \cdot$ Chung-Chuan Hsueh ${ }^{1}$ \\ Published online: 3 December 2020 \\ (C) Springer Science+Business Media, LLC, part of Springer Nature 2020
}

\section{Author Correction: Applied Biochemistry and Biotechnology https://doi.org/10.1007/s12010-020-03242-9}

The original version of this article unfortunately contained a mistake. There are some incorrect data in the ESM file. The correct ESM is attached in here.

The original article has been corrected.

Supplementary Information The online version contains supplementary material available at https://doi.org/ 10.1007/s12010-020-03474-9.

Publisher's Note Springer Nature remains neutral with regard to jurisdictional claims in published maps and institutional affiliations.

The online version of the original article can be found at https://doi.org/10.1007/s12010-020-03242-9

Bor-Yann Chen

boryannchen@yahoo.com.tw

\section{Chung-Chuan Hsueh}

cchsueh@niu.edu.tw

1 Department of Chemical and Materials Engineering, National I-Lan University, I-Lan 26047, Taiwan, Republic of China 